\title{
Saccadic eye movement applications for psychiatric disorders
}

This article was published in the following Dove Press journal:

Neuropsychiatric Disease and Treatment

13 September 2013

Number of times this article has been viewed

\author{
Juliana Bittencourt ${ }^{1-4}$ \\ Bruna Velasques ${ }^{1-3,5}$ \\ Silmar Teixeira ${ }^{1,2,4}$ \\ Luis F Basile 6,7 \\ José Inácio Salles ${ }^{5,8}$ \\ Antonio Egídio Nardi ${ }^{9}$ \\ Henning Budde ${ }^{10}$ \\ Mauricio Cagy" \\ Roberto Piedade' \\ Pedro Ribeiro 1,2,12
}

'Brain Mapping and Sensory Motor Integration Laboratory, Institute of Psychiatry, Federal University of Rio de Janeiro, ${ }^{2}$ Institute of Applied Neuroscience, Rio de Janeiro, ${ }^{3}$ Neurophysiology and Neuropsychology of Attention, Institute of Psychiatry, Federal University of Rio de Janeiro, Rio de Janeiro, ${ }^{4}$ Laboratory of Physical Therapy, Veiga de Almeida University, Rio de Janeiro,

${ }^{5}$ Neuromuscular Research Laboratory,

National Institute of Traumatology and

Orthopaedics, Rio de Janeiro, ${ }^{6}$ Division

of Neurosurgery, University of São Paulo

Medical School, São Paulo, ${ }^{7}$ Laboratory of

Psychophysiology, Department of Psychology and Phonoaudiology, Universidade Metodista do Estado de São Paulo (UMESP), São Paulo, ${ }^{8}$ Brazilian Volleyball Confederation, Rio de Janeiro, ${ }^{9}$ Panic and Respiration Laboratory, Federal University of Rio de Janeiro, Instituto Nacional de Ciência e Tecnologia (INCT) e Conselho Nacional de Desenvolvimento Científico e Tecnológico (CNPq), Rio de Janeiro, Brazil; ${ }^{10}$ Department of Sport Science and Physical Education, School of Science and Engineering, Reykjavik University, Reykjavik, Iceland; "Biomedical Engineering Program,

Coordenação dos Programas de Pós-

Graduação em Engenharia (COPPE), Federal

University of Rio de Janeiro, Rio de Janeiro;

${ }^{12}$ School of Physical Education, Bioscience

Department Escola de Educação Física e

Desportos da Universidade Federal do Rio de Janeiro (EEFD/UFRJ), Rio de Janeiro, Brazil

Correspondence: Juliana Bittencourt Universidade Federal do Rio de Janeiro (UFRJ), Rua Marquês de Abrantes, I 10 apto 210 Bloco C Flamengo,

Rio de Janeiro, RJ, Brazil

Tel +55 2l 85339778

Email juju_bitt@yahoo.com.br
Objective: The study presented here analyzed the patterns of relationship between oculomotor performance and psychopathology, focusing on depression, bipolar disorder, schizophrenia, attention-deficit hyperactivity disorder, and anxiety disorder.

Methods: Scientific articles published from 1967 to 2013 in the PubMed/Medline, ISI Web of Knowledge, Cochrane, and SciELO databases were reviewed.

Results: Saccadic eye movement appears to be heavily involved in psychiatric diseases covered in this review via a direct mechanism. The changes seen in the execution of eye movement tasks in patients with psychopathologies of various studies confirm that eye movement is associated with the cognitive and motor system.

Conclusion: Saccadic eye movement changes appear to be heavily involved in the psychiatric disorders covered in this review and may be considered a possible marker of some disorders. The few existing studies that approach the topic demonstrate a need to improve the experimental paradigms, as well as the methods of analysis. Most of them report behavioral variables (latency/ reaction time), though electrophysiological measures are absent.

Keywords: depression, bipolar disorder, attention-deficit hyperactivity disorder, schizophrenia, anxiety disorder

\section{Introduction}

"Saccadic eye movement" (SEM) is a short and rapid eye movement that can be voluntary or reflexive. It is responsible for capturing the image of interest then projecting it onto the fovea. ${ }^{1-3}$ Abnormalities in SEM can be seen in a variety of disorders, ${ }^{4,5}$ thus SEM is a sensitive instrument for analyzing some psychopathologies. Some individuals with mental disorders show irregularities in the process of sensorimotor integration and SEM patterns. As such, it is important to understand the functions of these processes to elucidate the pathophysiology of these disorders. ${ }^{6,7}$

SEM is considered a cognitive parameter to evaluate attention. Studies have showed that attention deficit is a feature of some mental disorders. ${ }^{8-17}$ Because of this, it is believed that patients with psychiatric disorders have different SEM patterns than healthy subjects. Saccade movement studies facilitate understanding of the neurobiological bases of some mental disorders, allowing the evaluation of the mechanisms involved in attention processes of this specific population. With this in mind, the presented literature review examined the saccadic paradigm in relation to sensorimotor integration and psychiatric disorders. In particular, the study analyzed the patterns of relationship between oculomotor performance and psychopathology, focusing on depression, bipolar disorder (BD), schizophrenia, attention-deficit hyperactivity disorder (ADHD), and anxiety disorder (AD). 


\section{Methods}

Scientific articles published from 1967 to 2013 in the following databases PubMed/Medline, ISI Web of Knowledge, Cochrane database and SciELO were reviewed. The keywords used to locate relevant articles were: "saccadic eye movement," "depression," "bipolar disorder," "attentiondeficit hyperactivity disorder," "schizophrenia," and "anxiety disorder." International articles published in English, Portuguese, and French during the defined period that contained some of the keywords were selected. Papers that observed non-human primates and humans were analyzed. Only research analyzing more than ten individuals, reviews, and original articles that used stimuli-guided saccades, antisaccades, memory-guided saccades, and smooth-pursuit eye movement (SPEM) tasks were included. Abstracts, case reports, articles in other languages, and papers that included other tasks that assessed attention not using eye movement were excluded.

\section{Paradigms for the investigation of SEM}

Due to the versatility of the saccades, a number of different behavioral tasks have been developed over the years to understand the different mechanisms involved in this process. ${ }^{18}$ Saccades have been investigated within several paradigms (Table 1). The most studied paradigms are visually guided saccade, antisaccade, and memory-guided saccade. ${ }^{19}$

\section{Visually guided saccades (pro- or reflexive saccades)}

The "prosaccade" is a response that involves a redirection of the gaze to a stimulus, which is generated to align the fovea with a target of interest; ${ }^{19,20}$ in other words, a visual stimulus appears randomly anywhere in the environment and guides the direction of the saccade. The successful completion of the task requires a simple and direct sensorimotor transformation generated by an external signal.

Table I Summary of the most common saccadic eye movement paradigms

\begin{tabular}{ll}
\hline Paradigm & Description \\
\hline Stimuli-guided saccade & $\begin{array}{l}\text { Redirection of the gaze toward a } \\
\text { stimulus in the environment } \\
\text { Spontaneous gaze redirection in the } \\
\text { opposite direction of stimuli, to suppress } \\
\text { an automatic saccade } \\
\text { Eemory-guided saccade }\end{array}$ \\
& $\begin{array}{l}\text { Eye direction toward stimulus alternates } \\
\text { between two fixed points at a fixed time } \\
\text { interval in the environment }\end{array}$ \\
\hline
\end{tabular}

Among the brain structures involved in this process, the superior colliculus plays an essential role in reflexive saccades. The activity is negatively related to latency; that is, the higher the activity of the superior colliculus, the faster the movement to search for the target. ${ }^{19,21}$ According to Johnston and Everling, ${ }^{20}$ when studying visually guided saccades, the lower the brain activity frequency during the reaction to a saccade at the beginning of a stimulus, the shorter the reaction time to the next saccade.

\section{Antisaccades}

This is the paradigm most often used in experiments investigating eye movement. Subjects look at a central fixed point during antisaccadic tasks. Instead of looking at the target when a peripheral signal appears, they are instructed to look quickly in the opposite direction, thus triggering a volunteer saccade of equal amplitude, which quickly and accurately suppresses the reflexive saccade. ${ }^{4,11,19-23}$ In addition, the task allows evaluation of the ability to suppress an automatic saccade. ${ }^{20}$ This suppression creates the perception of a stable environment. ${ }^{1,24}$

Response latencies are a typical measure used to assess antisaccades, as they are longer compared with those of reflexive saccades - by 50 milliseconds, on average ${ }^{19,22}-$ thus differing from other paradigms. ${ }^{25}$ The longer latency can be attributed to the time required to cause inhibition of a reflexive movement and coordinate the transformation of the volunteer reflexive process. ${ }^{22}$ This process of transformation requires changes in the activity level of the basic saccadic circuit and the activation and recruitment of new areas. ${ }^{7,26,27}$ Another widely used measure is the number of directional errors, which may reflect inhibition problems. ${ }^{25}$

The antisaccade results in increased activity in the frontoparietal cortex, frontal eye field (FEF), and supplementary eye field (SEF) compared with the prosaccade, but researchers have found that neurons in the FEF have a lower level of activity at the time of task preparation. ${ }^{19,20}$ However, the activity in the primary visual cortex is greater in antisaccade than in reflexive saccade. ${ }^{19}$

\section{Memory-guided saccades}

The "memory-guided saccade" is a classic task that has been used to investigate the neural processes underlying the performance of spatial memory, working memory and short-term memory. ${ }^{20,28}$ During this task, a stimulus alternates between two fixed points at a fixed time interval. The subject is instructed to look at a central fixed point. Alternating visual stimuli are then presented in the periphery of the visual field, 
requiring the subject to search for them in a sequential manner and remember their positions. ${ }^{4,28}$ Initially, there is a delay in displacement time between the central fixation point and the peripheral stimulus before the saccade begins. In the course of the task, anticipatory saccades occur, which are based on sensory and motor memory. ${ }^{19,28}$

This paradigm can be considered a procedural learning task that causes the subject to understand the predictability and the destination of the movement. Compared with stimulus-led movements, these movements are more complex because the activity requires use of memory combined with feed-forward and visual-information mechanisms. ${ }^{19,28}$ The area that facilitates the understanding of stimuli sequence is the pre-SEF, which contributes to the planning and memorization of a new task, while the SEF contributes to the execution of the sequences that are already memorized. ${ }^{19}$ The typical measures used to evaluate memory-guided saccades are accuracy (reflecting the localization of the target by the participant), the number of anticipation errors (reflecting problems in the inhibition system), and latencies. ${ }^{25}$

The systems responsible for memory-guided saccades that support the anticipatory behavior occurring during the task include the executive centers, such as the dorsolateral prefrontal cortex including the prefrontal and pre-supplementary cortex; special circuits related to memory, such as the frontoparietal and frontothalamic circuits, and the inferior hippocampal-parietal network; and the corticostriatal and cortical cerebellar handles that are involved in procedural learning. ${ }^{19,20,29}$

\section{Saccadic movements and psychiatric disorders: results}

This section presents the main research results linking psychiatric disorders with SEM. The main results are also summarized in Tables 2-5.

\section{Schizophrenia}

Picard et $\mathrm{al}^{30}$ conducted a study with 78 schizophrenic patients (43 non-treated and 35 treated) and 41 healthy controls, who were tested using three saccadic tasks (prosaccades, predictive saccades, and memory-guided saccades). The researchers analyzed whether difficulties in the execution of saccadic tasks correlated with neurological signs such as discreet lack of motor coordination, subtle deficiencies in the performance of sequences, unbalance, sensory integration, and persistence of primitive reflexes. The authors observed correlations between the latencies of the tasks, error rates in memory-guided saccades, and the prediction rate of the anticipatory saccades. No relationships were found in the group of healthy subjects, but, in the group of schizophrenic patients, the total points of neurological subtle signs were positively correlated with three variable saccades. Finally, negative correlations were found for the estimation rate of anticipated saccades.

Table 2 Summary of main findings in schizophrenic patients during execution of saccade paradigms

\begin{tabular}{|c|c|c|c|c|}
\hline Study & Objective & Subjects & Methods & Results \\
\hline $\begin{array}{l}\text { Sereno } \\
\text { and Holzman"l }\end{array}$ & $\begin{array}{l}\text { Examine the relationship } \\
\text { between antisaccade } \\
\text { and smooth pursuit } \\
\text { of the stimulus in } \\
\text { schizophrenic patients }\end{array}$ & $\begin{array}{l}\text { I7 schizophrenic patients } \\
\text { II non-schizophrenic } \\
\text { psychiatric patients } \\
\text { I4 normal controls }\end{array}$ & $\begin{array}{l}\text { Saccadic and smooth } \\
\text { pursuit were recorded }\end{array}$ & $\begin{array}{l}\text { Greater error rates } \\
\text { and greater delays in the } \\
\text { antisaccade task } \\
\text { Greater increase in error } \\
\text { rates in the antisaccade } \\
\text { pursuit performance } \\
\text { (schizophrenics with } \\
\text { impaired smooth pursuit) }\end{array}$ \\
\hline Picard et $\mathrm{al}^{30}$ & $\begin{array}{l}\text { Correlate neurological } \\
\text { soft signs with changes } \\
\text { in saccade movement } \\
\text { paradigms }\end{array}$ & $\begin{array}{l}78 \text { schizophrenic patients } \\
\text { ( } 43 \text { non-treated) } \\
4 \text { I healthy controls }\end{array}$ & $\begin{array}{l}\text { Subjects were tested } \\
\text { for three saccadic tasks } \\
\text { (prosaccade, predictive } \\
\text { saccade and memory- } \\
\text { guided saccade) } \\
\text { Infrared oculometry } \\
\text { was used }\end{array}$ & $\begin{array}{l}\text { Neurological soft signs and } \\
\text { saccades have common } \\
\text { mechanism and common } \\
\text { neural substrates }\end{array}$ \\
\hline Smyrnis et $\mathrm{al}^{64}$ & $\begin{array}{l}\text { Compare the reaction } \\
\text { time to execute a } \\
\text { saccade }\end{array}$ & $\begin{array}{l}53 \text { schizophrenic patients } \\
\text { I,089 controls }\end{array}$ & $\begin{array}{l}\text { The median and } \\
\text { variability of reaction } \\
\text { time were measured } \\
\text { for visually guided } \\
\text { saccades }\end{array}$ & $\begin{array}{l}\text { Increase in the patients' } \\
\text { median reaction time } \\
\text { Difference in information } \\
\text { processing }\end{array}$ \\
\hline
\end{tabular}


Table 3 Summary of main findings in bipolar disorder patients during execution of saccade paradigms

\begin{tabular}{|c|c|c|c|c|}
\hline Study & Objective & Subjects & Methods & Results \\
\hline Tien et $\mathrm{al}^{100}$ & $\begin{array}{l}\text { Examine multivariate } \\
\text { patterns of relationships in } \\
\text { oculomotor performance, } \\
\text { psychopathology, and } \\
\text { neuropsychology }\end{array}$ & $\begin{array}{l}29 \text { schizophrenic } \\
\text { patients } \\
26 \text { bipolar patients } \\
55 \text { healthy subjects }\end{array}$ & $\begin{array}{l}\text { Performance of smooth- } \\
\text { pursuit and SEM tasks was } \\
\text { assessed and analyzed in } \\
\text { relation to age, sex, and } \\
\text { different scales }\end{array}$ & $\begin{array}{l}\text { Higher proportion of errors } \\
\text { in the antisaccade task } \\
\text { Women had the worst } \\
\text { antisaccade performance } \\
\text { Scale scores had } \\
\text { independent associations } \\
\text { with the antisaccade task }\end{array}$ \\
\hline Gooding et $\mathrm{al}^{37}$ & $\begin{array}{l}\text { Conciliate the discrepant } \\
\text { results about visual } \\
\text { fixation performance in } \\
\text { schizophrenic patients }\end{array}$ & $\begin{array}{l}34 \text { schizophrenic } \\
\text { patients } \\
20 \text { bipolar patients } \\
30 \text { non-patient } \\
\text { controls }\end{array}$ & $\begin{array}{l}\text { Subjects were presented } \\
\text { with central fixation } \\
\text { targets }\end{array}$ & $\begin{array}{l}\text { The three groups did not } \\
\text { differ in terms of fixation } \\
\text { quality ratings }\end{array}$ \\
\hline $\begin{array}{l}\text { Gooding } \\
\text { and Tallent }{ }^{78}\end{array}$ & $\begin{array}{l}\text { Examine antisaccade and } \\
\text { working memory tasks in } \\
\text { schizophrenic and bipolar } \\
\text { patients }\end{array}$ & $\begin{array}{l}34 \text { schizophrenic } \\
\text { patients } \\
20 \text { bipolar patients } \\
30 \text { controls }\end{array}$ & $\begin{array}{l}\text { Execution of saccadic } \\
\text { inhibition (antisaccade), } \\
\text { working memory, and } \\
\text { sensorimotor tasks }\end{array}$ & $\begin{array}{l}\text { Antisaccade and working } \\
\text { memory deficits (in } \\
\text { schizophrenic patients) } \\
\text { More errors in the } \\
\text { antisaccade task, but normal } \\
\text { working memory task (with } \\
\text { bipolar patients) }\end{array}$ \\
\hline
\end{tabular}

Abbreviation: SEM, saccadic eye movement.

Another study recorded SEM and SPEM in 31 subjects: 17 schizophrenic patients, eleven non-schizophrenic psychiatric patients, and three normal controls. ${ }^{11}$ Both the schizophrenic subjects and psychiatric controls demonstrated a greater increase in error rates and greater delay in generating antisaccades than did normal controls. The researchers also analyzed individuals with alterations in their prefrontal areas, such as schizophrenic patients; the results showed that these subjects had difficulty initiating voluntary saccades toward the contralateral side in response to a visual stimulus and difficulty in suppressing reflexive saccades. The authors also reported that FEF was not essential to generate the saccade. Lesions in this area only produced transient and subtle deficiencies in eye movement generation. Combined lesions to the superior colliculus and FEF produced more significant and permanent changes, distorting the execution of eye movements. ${ }^{11}$

Holzman et $\mathrm{al}^{31}$ found that SPEM abnormalities in firstdegree relatives of schizophrenic patients only occur when the relatives have some schizophrenic spectrum characteristics. The researchers hypothesized that first-degree relatives of schizophrenic patients are vulnerable to these changes because they present the same phenotype. Moreover, Holzman et $\mathrm{al}^{32}$ observed that SPEM has been shown to be altered

Table 4 Summary of main findings in depressive patients during execution of saccade paradigms

\begin{tabular}{|c|c|c|c|c|}
\hline Study & Objective & Subjects & Methods & Results \\
\hline Sweeney et $\mathrm{al}^{39}$ & $\begin{array}{l}\text { Assess the executive } \\
\text { control of eye } \\
\text { movements and the } \\
\text { functional integrity of } \\
\text { cerebellar systems }\end{array}$ & $\begin{array}{l}29 \text { unmedicated } \\
\text { depressed inpatients } \\
19 \text { healthy subjects }\end{array}$ & $\begin{array}{l}\text { Battery of oculomotor } \\
\text { tasks }\end{array}$ & $\begin{array}{l}\text { Increased rates of response suppression } \\
\text { errors on an antisaccade task } \\
\text { Less accurate memory for spatial } \\
\text { location information in a spatial delayed } \\
\text { response task } \\
\text { Dysmetric visually guided saccades } \\
\text { Increased rates of saccadic intrusions } \\
\text { during visual fixation }\end{array}$ \\
\hline $\begin{array}{l}\text { Winograd- } \\
\text { Gurvich et } \text { al }^{40}\end{array}$ & $\begin{array}{l}\text { Explore the control and } \\
\text { execution of saccades } \\
\text { in melancholic and non- } \\
\text { melancholic depressive } \\
\text { patients }\end{array}$ & $\begin{array}{l}\text { I9 patients with major } \\
\text { depressive disorder } \\
\text { ( } 9 \text { melancholic; } \\
10 \text { non-melancholic) } \\
\text { I5 healthy controls }\end{array}$ & $\begin{array}{l}\text { A battery of SEM } \\
\text { tasks used to explore } \\
\text { reflexive saccades and } \\
\text { cognitive aspects of } \\
\text { saccades, including } \\
\text { inhibitory control } \\
\text { and spatial working } \\
\text { memory }\end{array}$ & $\begin{array}{l}\text { Longer latencies, difficulty in increasing } \\
\text { velocity peaks as target amplitudes } \\
\text { increased, and hypometric primary } \\
\text { saccades during the predictable } \\
\text { protocol (in melancholic patients) } \\
\text { Saccadic velocity peaks increased during } \\
\text { reflexive saccades at larger amplitudes } \\
\text { (in non-melancholic patients) }\end{array}$ \\
\hline
\end{tabular}

Abbreviation: SEM, saccadic eye movement. 
Table 5 Main findings in attention-deficit hyperactivity disorder (ADHD) patients during execution of saccade paradigms

\begin{tabular}{|c|c|c|c|c|}
\hline Study & Objective & Subjects & Methods & Results \\
\hline Gould et al ${ }^{17}$ & $\begin{array}{l}\text { Assess if eye movements } \\
\text { can be useful in providing } \\
\text { objective criteria for } \\
\text { evaluating ADHD, and if } \\
\text { they represent a stable } \\
\text { trait marker }\end{array}$ & $\begin{array}{l}53 \text { children with ADHD } \\
44 \text { healthy control children }\end{array}$ & $\begin{array}{l}\text { Fixation task with } \\
\text { large saccades away } \\
\text { from the fixation } \\
\text { point analyzed }\end{array}$ & $\begin{array}{l}\text { Larger saccades } \\
\text { interrupted fixation }\end{array}$ \\
\hline Feifel et $\mathrm{al}^{45}$ & $\begin{array}{l}\text { Evaluate the functional } \\
\text { integrity of the } \\
\text { frontostriatal system of } \\
\text { ADHD adult subjects }\end{array}$ & $\begin{array}{l}\text { I } 2 \text { adults with ADHD } \\
\text { unmedicated for at least } \\
48 \text { hours } \\
\text { I } 2 \text { normal comparison adults }\end{array}$ & $\begin{array}{l}\text { A comprehensive } \\
\text { battery of ocular } \\
\text { motor paradigms }\end{array}$ & $\begin{array}{l}\text { Significantly more } \\
\text { anticipatory saccades } \\
\text { during a prosaccade task } \\
\text { Significantly more } \\
\text { directional errors on the } \\
\text { antisaccade task }\end{array}$ \\
\hline
\end{tabular}

in about $70 \%$ of schizophrenics and about $45 \%$ of their firstdegree relatives.

Landgraf et $\mathrm{a}^{33}$ conducted a study in which memoryguided saccade, reflexive saccade, and central fixation tasks were administered to 16 patients who met the criteria for schizophrenia according to the Diagnostic and Statistical Manual of Mental Disorders, fourth edition (DSM-IV); ${ }^{34}$ 19 of these patients' psychiatrically healthy siblings; and 18 controls. The authors reported that in addition to the patients, their first-degree relatives also had a high number of errors for saccadic re-fixation tasks and guided memory saccadic tasks, reflecting a failure to inhibit reflexive saccades directed to a visible target.

A different experiment compared the reaction time to execute a visually guided saccade of 53 schizophrenic patients and 1,089 control subjects. ${ }^{35}$ An increase was verified in the patients' median reaction time. The researchers concluded that this difference in the distribution could be attributed to a basic difference in information processing, leading to the decision to move the eyes to the visually presented target. ${ }^{35}$

\section{$\mathrm{BD}$}

A study utilized the suppression of P50 auditory-evoked responses, inhibition of saccades during SPEM, and cancellation of reflexive saccades in the antisaccade, to evaluate and compare 40 bipolar patients, 18 schizoaffective disorder (bipolar-type) patients, and 29 schizophrenic patients. ${ }^{35}$ The study's objective was to determine if the patterns of endophenotype abnormalities differed between them, and if subjects with schizoaffective disorder (bipolar-type) were neurophysiologically more similar to subjects with schizophrenia or to subjects with BD. The results showed that patients with $\mathrm{BD}$ have difficulty in performing antisaccadic tasks due to a dysfunction in the activation of the prefrontal cortex, which is responsible for movement planning. This failure occurs because of alterations in the sensory transmission measures of P50, which supports the auditory system and the integrity of the interneuronal cholinergic modulation in the hippocampus, often altered in bipolar patients. ${ }^{35}$

Gooding et $\mathrm{al}^{36}$ examined the difference in behavior between ten bipolar and 23 schizophrenic patients during re-fixation and antisaccade tasks. The schizophrenic patients demonstrated moderately stable reaction times, accuracy, and mistakes over time. In contrast, bipolar patients do not show temporal stability and accuracy in the task or for the latencies of correct or incorrect answers.

Gooding et $\mathrm{al}^{37}$ researched 34 schizophrenic patients, 20 bipolar patients, and 30 non-patient controls. The objective of their study was to harmonize the discrepant results verified in previous studies about visual fixation performance in schizophrenic subjects. The patients were presented with central fixation targets. Analysis of variance of the number of saccades produced during fixation revealed that the three groups did not differ in terms of ratings of fixation quality.

Mueller et al ${ }^{12}$ studied young bipolar patients, comparing 20 youths with BD and 23 healthy subjects on a mixed proantisaccade task with monetary incentives. The participants were presented with three types of incentives: win money, lose money, or neither of these. Impaired reward processing was found in youths with BD compared with controls, particularly on antisaccades. This difference was reflected in lower error rates during incentive trials in the control but not in the BD group. By comparison, no group differences were found in terms of prosaccade movements.

Kathmann et $\mathrm{al}^{38}$ hypothesized a possible impairment of SPEM in unaffected family members of patients with 
affective disorders. To verify this hypothesis, 54 patients with schizophrenia or schizoaffective disorder, 46 patients with an affective disorder, 43 unaffected first-degree relatives of the schizophrenic patients, 36 unaffected first-degree relatives of the affective disorder patients, and 84 healthy subjects were compared when executing an eye movement task. A significantly lower pursuit gain was observed in the schizophrenia and affective disorder patients than in the healthy subjects. Moreover, the relatives of both the schizophrenia and affective disorder patients showed significant gain deficits. However, a gain deficit was observed in patients and in their unaffected biological relatives. This finding supports the existence of eye movement impairment in the relatives, but the sensitivity of this marker is too weak to be considered a genetic factor in schizophrenia and affective disorder patients.

\section{Depression}

Sweeney et $\mathrm{al}^{39}$ assessed depressed subjects through a battery of oculomotor tasks selected to evaluate the functional integrity of frontostriatal circuits and cerebellar vermis.
Twenty-nine non-medicated depressed inpatients and an ageand sex-matched healthy comparison group of 19 subjects were analyzed. The study verified that these patients presented an increased rate of error suppression in response to an antisaccadic task, a less accurate memory for spatial information, dysmetria in visually guided saccades and an increased rate of saccadic intrusion during visual fixation.

Winograd-Gurvich et $\mathrm{al}^{40,41}$ observed that depression patients exhibited greater latency and a higher number of errors when performing saccadic tasks. They also demonstrated a reduction in movement precision and difficulty suppressing peripheral target stimuli. These studies have determined that it is possible to differentiate motor disorders in melancholic and non-melancholic depression. Melancholic patients exhibit motor slowness, having difficulty in initiating movements without external cues. The researchers affirm that this performance of melancholic patients is similar to that of Parkinson's patients due to motor disturbances. It leads to increased latency, reduced peak velocity, and hypometric primary saccades. The increase of reprogrammed saccadic

Table 6 Summary of main findings in anxiety disorder (AD) patients during execution of saccade paradigms

\begin{tabular}{|c|c|c|c|c|}
\hline Study & Objective & Subjects & Methods & Results \\
\hline Siever et $\mathrm{al}^{47}$ & $\begin{array}{l}\text { Assess the accuracy of } \\
\text { SPEM prior to and after } \\
\text { administration of oral } \\
\text { amphetamine in } \\
\text { patients with OCD }\end{array}$ & $\begin{array}{l}5 \text { bipolar patients } \\
8 \text { OCD patients }\end{array}$ & $\begin{array}{l}\text { Comparison of error } \\
\text { rates and latencies } \\
\text { on a fixation task, } \\
\text { prosaccade task, and } \\
\text { antisaccade task }\end{array}$ & $\begin{array}{l}\text { In these I } 3 \text { patients, amphetamine did } \\
\text { not significantly alter the accuracy of } \\
\text { SPEM in the two patient groups } \\
\text { Negative correlations were observed in } \\
\text { the OCD patients and in the combined } \\
\text { patient groups between baseline SPEM } \\
\text { impairment and changes in eye-tracking } \\
\text { accuracy following amphetamine }\end{array}$ \\
\hline Spengler et $\mathrm{al}^{55}$ & $\begin{array}{l}\text { Investigate whether } \\
\text { specific oculomotor } \\
\text { dysfunctions can be } \\
\text { observed in patients } \\
\text { with OCD during the } \\
\text { execution of four kinds } \\
\text { of eye movement }\end{array}$ & $\begin{array}{l}18 \text { OCD patients } \\
16 \text { schizophrenic } \\
\text { patients } \\
23 \text { healthy subjects }\end{array}$ & $\begin{array}{l}\text { Evaluation of the } \\
\text { predictive saccade, } \\
\text { reflexive saccade, } \\
\text { antisaccade, and } \\
\text { predictive smooth } \\
\text { pursuit }\end{array}$ & $\begin{array}{l}\text { Increased rates of anticipatory saccades } \\
\text { with reduced amplitude gains (in OCD } \\
\text { and schizophrenic patients) } \\
\text { No changes in the latency or accuracy } \\
\text { of reflexive saccades (in OCD and } \\
\text { schizophrenic patients) } \\
\text { In the antisaccade task: no difference } \\
\text { in error rates and latencies (in OCD } \\
\text { patients and controls) and difference in } \\
\text { error rates and latencies (OCD patients } \\
\text { and schizophrenics) } \\
\text { No evidence for smooth-pursuit } \\
\text { maintenance impairment } \\
\text { Smooth-pursuit maintenance } \\
\text { performance impaired in OCD patients } \\
\text { whenever the predictability of the } \\
\text { stimulus movement was reduced }\end{array}$ \\
\hline Kloft et $\mathrm{al}^{56}$ & $\begin{array}{l}\text { Assess whether deficits } \\
\text { in the volitional control } \\
\text { of saccades in OCD } \\
\text { represents a cognitive } \\
\text { endophenotype }\end{array}$ & $\begin{array}{l}22 \text { unmedicated } \\
\text { patients with } O C D \\
22 \text { unaffected first- } \\
\text { degree relatives of } \\
\text { OCD patients } \\
22 \text { healthy volunteers }\end{array}$ & $\begin{array}{l}\text { Four task types: visually } \\
\text { guided saccades and } \\
\text { three different types of } \\
\text { volitional saccade } \\
\text { tasks - cued, un-cued, } \\
\text { and free choice }\end{array}$ & $\begin{array}{l}\text { OCD patients and relatives of OCD } \\
\text { patients had longer latencies in the } \\
\text { volitional saccades (un-cued condition) } \\
\text { No group differences in latencies of } \\
\text { volitional (cued condition), visually } \\
\text { guided, and free-choice saccades }\end{array}$ \\
\hline
\end{tabular}

Abbreviations: OCD, obsessive-compulsive disorder; SPEM, smooth-pursuit eye movement. 
latencies and the severity of melancholic symptoms may reflect a deficiency in the ability to select or inhibit the responses to competing targets. The researchers observed similar control results in patients with non-melancholic depression, but the peak velocity as well as the amplitudes of the reflexive saccade increased. Further, melancholic patients present a higher latency and a lower peak velocity in the execution of a memory-guided saccade, replicating results observed in stimulus-guided saccades.

An experiment using therapeutic repetitive transcranial magnetic stimulation (rTMS) was conducted to examine the influence of this on different types of saccades in patients treated for major depression. The latency and directional error were analyzed in reflexive and voluntary saccades (ie, prosaccades and antisaccades). The tasks were studied in eleven depressed patients before and after rTMS. The eye movement was registered by infrared oculography. After applying ten sessions of rTMS on the left dorsolateral prefrontal cortex, new measures were adopted to observe modifications. A decrease in the antisaccade task latency occurred after rTMS application, but the stimulation in this cortex seemed to have no important effectiveness on reflexive saccades. The voluntary prosaccades were also not influenced. These results suggest that rTMS might differentially affect specific aspects of saccade behavior. ${ }^{42}$

Mahlberg et a ${ }^{43}$ investigated the basic neurophysiologic parameters of saccades in schizophrenics, patients with major depression, and nonpsychiatric controls. The precision, peak velocity, and reaction time were considered for comparison. The velocity peak significantly increased in schizophrenic patients. Depressive patients had a longer reaction time. The patients exhibited more corrective saccades than controls. In contrast, Flechtner and colleagues ${ }^{44}$ evaluated schizophrenic patients and patients with affective disorders (major depression) during clinical treatment. Subjects were evaluated during execution of eye movement tasks; specifically, the velocity gain was evaluated in different saccadic categories. No significant correlations were found between psychopathological status, neuroleptic medications, and eye movement variables. Based on this finding, the researchers concluded that psychiatric patients' task performance was not affected by the use of the neuroleptics or by clinical status.

\section{ADHD}

Feifel et $\mathrm{a}^{45}$ aimed to evaluate the functional integrity of the frontostriatal system of adult subjects with ADHD. The ADHD adult subjects, unmedicated for at least 48 hours, and normal comparison adults were studied by means of a comprehensive battery of ocular motor paradigms. During a prosaccade task, the ADHD subjects generated significantly more anticipatory (premature) saccades with reaction time of less than 90 milliseconds. In the antisaccade task, the ADHD subjects made significantly more directional errors than the normal adults. However, the performance of the adults with ADHD was consistent with deficits in saccadic inhibition. Therefore, the study concluded that there is interdependence between the brain systems mediating visual attention and ocular motor behavior.

A study related that problems presented by these patients during the performance of saccades are caused by abnormal selection and maintenance of motor response to stimuli, due to a failure to inhibit or delay behavioral responses. Goto et $\mathrm{al}^{46}$ investigated the development of reflexive and voluntary control of saccades in normal children to clarify dysfunctional nervous systems in ADHD individuals, comparing saccade parameters among 19 ADHD patients, 50 normal subjects, and four patients with frontal lesion. Latency and precision were computed, the percentage of anticipatory errors was determined in memory-guided saccade tasks, and the percentage of direction errors was determined in antisaccade tasks. The results showed that ADHD patients present dysfunctions in "response inhibition," which is modulated by the frontal lobe.

Gould et al ${ }^{17}$ compared 53 children with ADHD (29 girls and 24 boys) with 44 healthy control children (18 girls and 26 boys) on a 21 -second fixation task. The saccades used for comparison were large saccades; in other words, saccades larger than $4^{\circ}$ away from the fixation. It was observed that children with ADHD made larger saccades that interrupted fixation than did control children $(P=0.001)$. Mean scores of the ADHD group did not change significantly with subsequent retesting with placebo $(P=0.11)$; however, there was poor intra-subject correlation $(r=0.16)$. The ADHD children made significantly more intrusive saccades during fixation than did the control subjects, possibly reflecting intrinsic neurologic dysfunctions.

\section{AD \\ Obsessive-compulsive disorder (OCD)}

Siever et $\mathrm{al}^{47}$ evaluated the relationship between SPEM and the attentional effects of amphetamine. SPEM performance was measured prior to and following amphetamine administration in five bipolar patients and eight obsessive-compulsive patients. Amphetamine did not significantly alter the accuracy of SPEM in the two patient groups. However, significant negative correlations were observed in the obsessive-compulsive patients and in the combined patient groups between baseline 
SPEM impairment and changes in eye-tracking accuracy following amphetamine; that is, individuals with poorer SPEM accuracy improved, while the tracking accuracy of better SPEM performers was lowered during amphetamine treatment.

Clementz et al ${ }^{48}$ conducted two studies to evaluate the smooth-pursuit system functioning of OCD patients. In the first study, 12 OCD patients and 12 nonpsychiatric subjects were administered $9 \%$ second ramp stimuli to elicit SPEM. Patients with OCD did not significantly differ from nonpsychiatric subjects in terms of pursuit gain or frequency of corrective and intrusive saccades. They also observed that OCD patients had smaller catch-up saccades during smooth pursuit than nonpsychiatric subjects. In the second study, 12 OCD patients and 12 nonpsychiatric subjects were administered two different triangle wave stimuli. Patients with OCD and nonpsychiatric subjects did not significantly differ in any variable in the slow target velocity condition. However, when following $24 \%$ second targets, patients with OCD had significantly lower pursuit gain than the nonpsychiatric subjects.

Pallanti and colleagues ${ }^{49}$ investigated the existence and characteristics of SPEM disturbances (in both saccadic and smooth pursuit) in unmedicated OCD patients, and the correlation between SPEM and clinical features, such as previous treatment, severity, and duration of illness. In that study, 21 OCD patients and 21 community-recruited controls were tested for multiple target velocity. The authors verified a SPEM alteration in some OCD patients, which consisted of a moderate to severe reduction of pursuit and increased number and amplitude of anticipatory saccades.

To investigate whether the abnormalities in the orbital prefrontal cortex are involved in causing obsessive and compulsive symptoms, Rosenberg et $\mathrm{al}^{50}$ administered oculomotor tests to 12 medication-free, non-depressed patients with OCD aged 18 to 44 years and 12 matching healthy controls to assess ability to suppress responses and execute delayed volitional responses. Patients with OCD had more responsesuppression failures than controls when peripheral visual targets were presented close to central fixation.

In a study comparing 20 OCD patients, 20 schizophrenics, and 20 healthy controls during the execution of smooth-pursuit and steady-state tasks, ${ }^{51}$ Farber et al found that OCD and nonpsychiatric individuals had statistically similar pursuit reaction time and average eye accelerations during open- and closed-loop performances. The researchers suggested that brain regions supporting smooth-pursuit performance are unimpaired among OCD patients.
Maruff et $\mathrm{al}^{52}$ investigated 12 patients with OCD and 12 controls during visually guided saccade, volitional prosaccade, and antisaccade tasks. They did not find any difference between groups in terms of antisaccade error rates. The latency of visually guided saccades did not differ between groups; however, the latency of both volitional prosaccades and antisaccades was significantly longer in the patients with OCD compare to controls.

Lencer et $\mathrm{al}^{53}$ recorded eye movements in 16 patients with schizophrenia, 15 with affective disorder, 18 with OCD, and 23 healthy control subjects using infrared reflection oculography. The authors observed a lower steady-state velocity in the foveofugal task in all patient groups than in controls; changes in saccadic latencies or position errors were not found in any of the patient groups. In addition, pursuit latency remained unchanged and initial eye acceleration did not decrease. The researchers did not find any difference among the OCD and other patient groups.

Van der Wee et $\mathrm{al}^{54}$ compared 14 adult psychotropicnaive, comorbidity-free patients with OCD and 14 pair-wise healthy controls on prosaccade, antisaccade, and active fixation tasks, in which subjects only had to suppress reflexive prosaccades. The study did not find any difference between patients with OCD and healthy controls in terms of error rates on the active fixation and saccadic tasks, which indicates that OCD patients have no gross impairment of oculomotor inhibitory capacities. However, the authors found an abnormal increase in latency for the antisaccade task in patients with OCD. They concluded that, at present, there is no available evidence about the state or trait-dependent nature of this specific oculomotor abnormality or about its presence in subsyndromal populations or in relatives of OCD patients.

Spengler et $\mathrm{al}^{55}$ investigated whether specific oculomotor dysfunctions can be observed in patients with OCD during the execution of four kinds of eye movements: predictive saccade, reflexive saccade, antisaccade, and predictive smooth pursuit. The sample included 18 OCD patients, 16 schizophrenic patients, and 23 healthy subjects. The authors identified increased rates of anticipatory saccades with reduced amplitude gains in patients with OCD, similar to the findings observed in schizophrenic patients. They did not observe changes in the latency or the accuracy of reflexive saccades for OCD patients and schizophrenics. In the antisaccade task, error rates and latencies observed in the OCD patients did not differ from those of healthy controls, but did differ from those seen in schizophrenic patients. Further, the authors did not find evidence for smooth-pursuit maintenance impairment; however, smooth-pursuit maintenance performance seemed 
to be impaired in OCD patients whenever the predictability of the stimulus movement was reduced.

Kloft and colleagues ${ }^{56}$ investigated 22 unmedicated patients with OCD, 22 unaffected first-degree relatives of OCD patients, and 22 healthy volunteers. The study involved four task types: visually guided saccades and three different types of volitional saccade task: cued, un-cued, and free choice. The researchers identified that OCD patients and relatives had longer latencies in the volitional saccades with demand than the control group. They also found that there were no group differences in terms of latencies of volitional saccades without response selection demand (cued condition), visually guided saccades, and free-choice saccades. The study provides evidence that dysfunctional volitional response selection is a candidate OCD endophenotype.

\section{Social anxiety}

Wieser et $\mathrm{al}^{57}$ investigated an emotional saccade task with facial expressions (happy, angry, fearful, sad, neutral) in socially anxious individuals. The participants performed either pro- or antisaccades in response to peripherally presented facial expressions. The results showed that socially anxious persons have difficulty in inhibiting themselves to reflexively attend to facial expressions; they made more erratic prosaccades to all facial expressions when an antisaccade was required. Thus, these findings indicate impaired attentional control in social anxiety. This result may be due to a dysfunction in the prefrontal areas, since they are involved in attentional control.

\section{Anxiety (nonspecific)}

Ansari et $\mathrm{al}^{58}$ tested the hypothesis that anxiety impairs performance in cognitive tasks that involve the shifting function of working memory through the antisaccade paradigm. The participants performed single- and mixed-task versions of the paradigm. The single task involved the completion of separate blocks of anti- and prosaccade trials, while, in the mixed task, participants completed anti- and prosaccade trials in a random order within blocks. The authors observed that individuals in the high anxiety group did not exhibit the commonly reported paradoxical improvement in saccade latency, whereas those in the low anxiety group did.

Derakshan et $\mathrm{al}^{59}$ investigated the effects of anxiety on the antisaccade task. In two experiments, participants in the high anxiety group had longer antisaccade correction latencies than participants in the low anxiety group and this effect was greater with threatening cues than with positive or neutral ones. The high and low anxiety groups did not differ in terms of error rate in the antisaccade task, nor were any group differences found in terms of latency or error rate in the prosaccade task. The researchers concluded that anxiety affects performance efficiency but not performance effectiveness. The summary of the main findings are presented in Table 6.

\section{Discussion}

Our hypothesis is that patients with the approached psychiatric disorders have different SEM patterns when compared with healthy subjects. The aim of this study was to study the saccadic paradigm in relation to sensorimotor integration and psychiatric disorders; specifically, to analyze the relationship patterns between oculomotor performance and depression, $\mathrm{BD}$, schizophrenia, ADHD, and AD. However, it is important to highlight that the present review shows that there is a difficulty in establishing a pattern of response tasks using eye movements related to different psychiatric disorders. This difficulty can be mainly explained by two factors: the use of (1) medications and (2) different methodologies for the evaluation process.

First, therefore, the fact that psychiatric patients are on medications must be considered, as these drugs can alter the response required by the tasks in the different experiments. ${ }^{60-62}$ Further, for ethical reasons, psychiatric patients cannot be asked to suspend use of the medications. The second factor is that research using eye movements to evaluate patients employs different measures to carry out these analyses. Lack of standardization of these measures could influence the results, which have been presented in different manners. As such, it is necessary to establish a standard methodological approach for the different pathologies highlighted in the study in order to find a consensus about the changes displayed in each. This review identified the following methods as a strategy assessment for eye movements: electrooculography (electrooculogram), infrared oculometry, video camera, limbus eye-tracking device, remote mounted eye tracker, $\mathrm{V}$ dual-Purkinje tracker, microelectrodes, and others.

\section{Schizophrenia}

Schizophrenia is a chronic disabling syndrome that affects $1 \%$ of the population. It is the main cause of psychiatric hospitalization and is characterized by hallucinations, delirium, paranoia, and severe mood disorders among other symptoms. ${ }^{63}$ Schizophrenic patients exhibit more hypoprosexia when responding to a variety of stimuli; ${ }^{64}$ this has been associated with reduced gray-matter volume in the prefrontal, frontal, temporal, and parietal areas, which are responsible for sequencing tasks, motor coordination, and 
sensory integration, respectively. ${ }^{30}$ In particular, these regions control reflexive glance inhibition during the performance of specific eye movement tasks. ${ }^{10}$

A recent study verified abnormalities in schizophrenic patients, where decreased widespread gray-matter density reductions were observed. ${ }^{65}$ The study also verified that abnormal smooth pursuit and SEM in schizophrenia were associated with specific brain structures. The study highlighted changes in occipito-temporo-frontal circuitry, the left calcarine cortex, the left cuneus, the left superior occipital cortex, the left superior frontal gyrus, the left cerebellum, the right lingual cortex, the right middle occipital cortex, the right inferior temporal cortex, the right dorsolateral prefrontal cortex, and bilateral precentral gyri extending to the FEFs. ${ }^{65}$ Some of these areas are involved with attention mechanisms and with eye movements. It is necessary to consider that attentive disorders are also often associated with schizophrenia and could conceivably affect the execution of an antisaccade and cause abnormalities in SPEM. 5,10,11,66

The most common types of eye movements used to explore the environment are saccades and smooth pursuit. Saccades are normally of high velocity and are used to rapidly change eye position in order to foveate new targets of interest, while smooth pursuit attempts to match the velocity of the eye with the target velocity in order to foveate targets during motion. ${ }^{67,68}$ The neuronal pathways involved in these movements send afferents originating from the same retinal inputs to some areas. Studies highlight that certain regions are more involved than others depending on the movement; for example, the rostral bank of the arcuate sulcus in the FEF is more active during saccadic tasks, and the posterior wall of the arcuate sulcus in the FEF is predominant during SPEM. ${ }^{67}$ This is observed in healthy subjects. A study evaluated the differences in cerebral activation during smooth pursuit and SEM using positron emission tomography and observed that subjects exhibited frontal eye-field activation during both smooth pursuit and SEM, but that it was greater in the latter. During smooth pursuit, subjects also exhibited increased cerebral activation in the left temporal-occipital border and left superior frontal cortex and decreased activation in the medial superior parietal and insular regions related to the saccades. Other cortical visual and eye movement brain regions also demonstrated differences in activation between the two visual tasks. ${ }^{69}$

Researchers have shown that schizophrenic patients have an increased latency in performing SEM when trying to correct for an error produced during the task. This finding is due to a reduced cortical inhibition reflex, which is caused by failures in spatial integration and memorization. This deficit leads to a difficulty in incorporating visual-spatial information into working memory, causing limitations to the use of information early in the modification of the planned saccade. ${ }^{4,11,30,35,36}$ These abnormalities in SPEM and antisaccade have also been reported in relatives of patients with schizophrenia. ${ }^{66,70}$ The eye-tracking deficits have been proposed as markers for a genetic vulnerability to schizophrenia. ${ }^{66}$ Poor performance in the antisaccade task has been proposed as a candidate endophenotype in schizophrenia. ${ }^{71}$ In their study, Mazhari and colleagues ${ }^{71}$ observed the antisaccadic performance in schizophrenic patients and their relatives. The authors compared schizophrenic patients with and without cognitive deficits, relatives, and healthy controls during the task. They observed greater error rate and prolonged latencies to correct high error rates in relatives of poorly performing patients; longer latencies of self-correction saccades in relatives than in controls; and higher error rates and longer latencies of self-correction saccades in the individuals with cognitive impairments than in individuals without cognitive deficits. ${ }^{71}$ The eye movements have also been utilized to identify individuals with an increased risk of developing a psychosis. An experiment identified that both the corrective and non-corrective saccadic rates during pursuit were higher in people at higher risk of developing psychosis. The results of this study indicate that abnormalities in SPEM are already present in these patients, prior to the first psychotic episode. ${ }^{66}$

Experiments have verified that correlations between changes in SEM and schizophrenia could have been misinterpreted, because the same performance errors found in schizophrenic patients are seen in patients with other psychiatric disorders. This may be because these characteristics are linked to attention disorders, difficulty in understanding, and lack of motivation. These are common characteristics in all patients with psychopathological impairments. ${ }^{10,72}$ Disturbances in the implementation of an antisaccade cannot have a high degree of specificity for the diagnosis of schizophrenia, because the frontostriatal system, which controls cognitive ability, may be involved in psychotic and nonpsychotic disorders. ${ }^{14}$ The cause of these alterations suggests that there may be anomalies in the eye pursuit system in conjunction with schizophrenia. $^{72}$

Thus, we concluded that sensorimotor integration and ocular tracking disorders seem to be involved with one of the pathophysiological characteristics of schizophrenia. Schizophrenic patients have difficulty inhibiting stimuli from the environment and directing attention to the target stimuli. There is still no absolute agreement among researchers, 
but it seems that many of these physiological deficits are independent and not interconnected. However, these deficits may be tools to identify characteristics of psychotic disorders, to clarify the pathophysiologies, and to identify new approaches for treatment. Thus, more research is needed to assess whether changes in saccadic movement patterns can constitute a pathognomonic signal of schizophrenia.

\section{$\mathrm{BD}$}

$\mathrm{BD}$ is characterized by oscillation between manic, hypomanic, euthymic, and depressive states. Patients also display an alteration in cognitive control that interferes with functionality. ${ }^{12,72-74}$ This pathophysiology is poorly understood ${ }^{12}$ and research seeks to clarify the central mechanisms involved in this disorder through eye movement studies. ${ }^{12,35,72}$

The results of studies using SEM in patients with BD are conflicting, yet some of them indicate abnormalities in ocular pursuit tasks. ${ }^{72}$ Although the neural basis of BD is not yet fully known, researchers suggest that the cause of errors may be related to a hypofunction of the striatum cortex. ${ }^{10}$ Other evidence supports the fact that the cerebellum mediates the activity of other brain areas involved in the control of eye movements, specifically through the vermis, flocculi, paraflocculi, and deep cerebellar nuclei. ${ }^{75,76}$ A study utilizing functional magnetic resonance evaluated the performance of bipolar subjects during SPEM tasks. ${ }^{77}$ The research identified a greater hemodynamic in the cerebellar vermis of the bipolar subjects (in specific patients with symptoms of depression) than in healthy subjects. The authors suggested that this may imply a cerebellar involvement in BD. ${ }^{77}$ Functional magnetic resonance studies also provide evidence that the cerebellar hemispheres play a significant role in smooth pursuit and SEM. ${ }^{75}$ Other studies have shown that changes in saccadic movement in BD are influenced by phasic characteristics, specifically by the oscillations typical of the patient's clinical condition, which interferes with the status of his/her personality. ${ }^{78}$ In some cases, these mood swings can take place even within the same day, making it difficult to analyze the results, which often show inconsistencies, depending on the patient's emotional condition. This oscillation influences the performance of the task by generating a greater or lesser number of errors and changes in the latencies of these patients. ${ }^{36}$ Studies report that bipolar patients, unlike schizophrenic patients and healthy subjects, exhibit a decrease in latency that translates into a faster response to stimulation. ${ }^{12,33}$ Alterations in response time can help the different diagnosis of this disorder. ${ }^{33}$ However, another study found that bipolar patients demonstrated normal latency and accuracy for simple visually guided saccadic tasks. ${ }^{39}$ In reflexive saccadic tasks, bipolar patients did not show any impairment in precision movements, not even at peak velocity, but increased latency for other tasks was observed. ${ }^{39}$

After analysis of the available studies, one can observe that there is an enormous research gap, with numerous questions still existing about the behavior of bipolar patients during tasks involving attention and eye movements. The bipolar patients in the studies presented different responses in relation to saccadic movement modifications. These responses appear to depend on the phase of the disease in which the patient is. There is a need to develop new experimental studies looking at patients in various states of mood swing to clarify these uncertainties, thus providing a greater understanding of the pathophysiology, which will allow for the development of new treatments approaches for these patients.

\section{Depression}

Depression is characterized by a slowing of mental processes, depressed or irritable mood, anhedonia, fatigue, indifference, psychomotor apathy or agitation, and life cycle change. ${ }^{79-81}$ The cognitive and motor assessment of depressed patients through oculomotor tasks is essential for establishing the involvement of the central nervous system in this process. ${ }^{40,41}$ Tasks that involve SEM provide an accurate assessment of cognitive control, which is influenced by the attention processes. ${ }^{27,82}$ These measures can be affected by motivational and emotional factors relevant to attention deficits related to depressive disorders. ${ }^{13,14}$ Systematic assessment of oculomotor function represents a promising strategy for the testing of executive motor deficits in order to understand the multiple systems involved in depression. In particular, eye movements are easily observable and measurable, thus directly provide information about the nervous system. ${ }^{39}$

Depression is associated with a pattern of disinclination in preparing for saccades and subsequently controlling their execution. ${ }^{13}$ Moreover, these patients have low levels of motivation, which influences attention engagement. ${ }^{13}$ Antisaccadic tasks may allow for the assessment of deficiencies prior to the onset of depressive symptoms, observing whether these constitute vulnerability factors or contribute to the manifestation of symptoms. ${ }^{13}$ When comparing saccadic tasks in depressed patients with those possessing other psychiatric illnesses, it was found that, in contrast to schizophrenia, depressive patients present more stable cognitive impairments and their saccadic movement appears to vary with mood. ${ }^{39}$ In relation to the impairment of the eye movement pattern in psychiatric patients' relatives, some researchers 
have sought to verify if their first-degree relatives with affective disorders also show changes in SPEM pattern, as observed in relatives of schizophrenics. The research results are controversial. One study found that the pattern of SPEM performed by the relatives of depressed patients showed no significant difference when compared with that of individuals with no family history of major psychosis, suggesting that this impairment is characteristic of first-degree relatives of schizophrenic patients and not of relatives of patients with affective disorders. ${ }^{83}$ However, Kathmann et $\mathrm{al}^{38}$ found a gain deficit in SPEM in the unaffected relatives of patients with affective disorders, suggesting that eye-tracking disorders are not specific to schizophrenia.

Thus, the eye movement pattern of depressed patients seems to vary with mood. Moreover, these patients exhibit slow responses to the stimulus and vary in their response according to their type of depression.

\section{ADHD}

When approaching ADHD, it is important to differentiate this concept from that of attention-deficit disorder (ADD) to avoid confusion. ADD is characterized as a non-hyperactive subtype of ADHD; however, in this paper, ADHD will be discussed in its general form. ${ }^{84}$ ADHD is characterized by the presence of inattention, hyperactivity, and impulsivity, associated with inappropriate behavior. ${ }^{15-17}$ Children affected by this disorder have problems related to task executive control and inhibition processes. They fail to execute planned behaviors, which rely on the use of internal representations. ${ }^{25,85}$ Further, they demonstrate difficulty in performing tasks of working memory and exhibit decreased velocity in motor and cognitive activities. ${ }^{25,86}$ Research correlates this pathology with changes in the architecture of the frontal lobes, caudate nucleus, and corpus callosum. ${ }^{18,83}$ Due to these dysfunctions, neural circuits are affected in ADHD, mostly the frontostriatal and frontoparietal ones. ${ }^{18,87}$ Imaging exams reveal structural and functional abnormalities in the basal ganglia-thalamiccortical circuitry, which transmits information to the frontal cortex and the frontostriatal network. ${ }^{46}$

One other feature in patients with ADHD is distractibility. Distractibility and inattention have been considered a possible cause of variability in response time involved in saccadic tasks. ${ }^{88,89}$ A study comparing healthy subjects with ADHD patients verified that the ADHD group was slower to inhibit reflexive saccades than the control group, and slower reaction time and more errors were observed in the former group.$^{88} \mathrm{~A}$ delayed oculomotor response was identified in the patients, who displayed more premature saccades than the controls. The result was associated with distraction increase and it was considered an effective measure for selective attention, particularly in the ADHD population. ${ }^{88}$

The study of saccades through paradigms associated with ADHD patients has helped understanding the pathophysiological basis of the disorder. ${ }^{90}$ These studies have been used to assess the ability of these patients to generate or inhibit a reflexive saccade and induce voluntary responses, ${ }^{18}$ allowing researchers to observe the working memory, spatial attention, and expectation. ${ }^{46,90}$ Tasks using SEM have been widely employed to verify the process of inhibition in people with ADHD. Good performance in executing the tasks requires inhibition and motor reprogramming. ${ }^{90}$

Patients with ADHD exhibit a higher error rate during antisaccadic tasks. ${ }^{15,18}$ This abnormality is caused by a deficiency in the dorsolateral prefrontal cortex and basal ganglia. These patients exhibit less precision in the execu-


with healthy subjects, who seem to expect the location of the stimulus and do not act impulsively. ${ }^{45,90}$ Individuals with ADHD have difficulty maintaining a prolonged fixation on a target and in predicting the task interval time. ${ }^{18,25,45,46}$ They also have great difficulty regulating the process of initiating a saccadic movement, but their saccades are metrically normal, suggesting that the brainstem is the generator of the movement and is intact in such cases. These characteristics are similar to the alterations present in people with lesions of the frontal lobe. Some researchers correlate this with failures in the top-down control of attention. ${ }^{17,18,25,90}$ Changes in latency are also observed; ADHD patients exhibit longer latencies with reduced accuracy, due to their attempt to correct the error of the saccades and regulate the onset of the task. ${ }^{18,25}$

It is necessary to amplify the inhibition signals to suppress a saccade, thus reducing the excitability of the neurons responsible for triggering the eye movement. ${ }^{18}$ Inhibition is a prominent cognitive domain. ${ }^{87}$ Therefore, in relation to eye movement tasks, subjects with ADHD demonstrated difficulty executing the planned movements and had impulsive responses. The research studies that correlate the saccade with ADHD are promising because they allow for analysis of the disease pathophysiology, but it is necessary to go deeper with these studies to better understand the inhibition alterations presented by these patients.

\section{$A D$}

"AD" is a chronic condition characterized by an excessive and persistent sense of apprehension. ${ }^{92}$ The DSM-IV divides the $\mathrm{AD}$ into different subtypes, including generalized AD, panic 
disorder, agoraphobia, social anxiety disorder, OCD, specific phobias, and post-traumatic stress disorder. ${ }^{93}$ Several studies have demonstrated cognitive changes in patients with $\mathrm{AD}$, especially attention deficit. ${ }^{94-96}$ One way to investigate attention deficit is to understand abnormalities in eye movement. In this context, few studies have aimed to observe the relation between eye movement and anxiety. A review published in 2011 examined studies that investigated the contribution of eye movement to the neuropsychology of OCD. ${ }^{99}$

A previous review reported a small but growing body of publications investigating eye movement and AD. ${ }^{97}$ The most investigated form of AD is OCD; most of the studies try to correlate eye movement deficit with impaired prefrontal circuit in this population. Since this review, we found just one original article relating eye movement and OCD. ${ }^{56}$ This fact reinforces the need for more studies that seek to investigate this issue. As observed by previous reviews, most studies involving eye movement have investigated OCD and anxiety patients, demonstrating a change in latency during the execution of the eye movement when compared with control subjects. This fact has been confirmed by the strong correlation of dysfunctional areas in OCD and the areas involved in motor control.

Based on the knowledge that cortical areas driving predictive saccades overlap with circuits involved in the pathophysiology of OCD (ie, pathways from prefrontal areas to the basal ganglia), ${ }^{98,99}$ most of the studies tried to investigate if OCD patients have some deficit in the eye movement. Four studies investigated SPEM in OCD patients. ${ }^{47-49,51}$ Although they examined the same kind of eye movement, we verified a wide variation in the paradigms, tasks, and objectives of the studies. Because of this, it is difficult to define a SPEM deficit pattern in OCD patients. One study observed amphetamine's attentional effects in OCD patients and verified a significant negative correlation in obsessivecompulsive patients between baseline SPEM impairment and changes in eye-tracking accuracy following amphetamine; that is, individuals with poorer SPEM accuracy improved, while the tracking accuracy of better SPEM performers deteriorated during amphetamine treatment. ${ }^{47}$ Clementz et $\mathrm{al}^{48}$ did not observe any difference between OCD patients and nonpsychiatric subjects in terms of pursuit gain, frequency of corrective, intrusive saccades, or any variable in the slow target velocity condition. However, they observed that OCD patients had smaller catch-up saccades during smooth pursuit and lower pursuit gain than nonpsychiatric subjects. Pallanti et $\mathrm{al}^{49}$ also observed a moderate to severe reduction and increased number and amplitude of anticipatory saccades in some OCD patients. In contrast, Farber and colleagues ${ }^{51}$ showed that OCD and nonpsychiatric individuals had statistically similar pursuit reaction times and average eye accelerations during open- and closed-loop performances, suggesting that brain regions supporting smooth-pursuit performance are unimpaired in OCD patients.

Four other studies investigated SEM tasks in OCD patients. Maruff et $\mathrm{al}^{52}$ used three tasks: visually guided saccade, a volitional prosaccade, and antisaccade, and only observed that OCD patients presented a slower latency than controls in volitional prosaccades and antisaccades; they did not find any difference in other parameters. Using prosaccade and antisaccade tasks, van der Wee et al ${ }^{54}$ also found a slowing in latency for the antisaccade task in patients with OCD. In a more recent study, Kloft et $\mathrm{al}^{56}$ identified that OCD patients and relatives had longer latencies in the volitional saccades than the control group. However, Spengler et al ${ }^{55}$ did not observe any difference between OCD patients and controls during predictive saccade, reflexive saccade, and antisaccade tasks. Two more studies have investigated oculomotor tests in OCD patients. One found that OCD patients had more response-suppression failures than controls when peripheral visual targets were presented close to central fixation, ${ }^{50}$ while the other observed a lower steady-state velocity in the foveofugal task in patients than in controls; changes of saccadic latencies or position errors were not found in any of the patient groups. ${ }^{53}$

We found only one study that investigated eye movement deficits in social anxiety and two studies that examined anxiety not as a disorder, but simply divided the sample into low and high anxiety groups. The socially anxious individuals studied had difficulties in inhibiting themselves to reflexively attend to facial expressions, and they made more erratic prosaccades to all facial expressions when an antisaccade was required. ${ }^{57}$ The researchers investigated the relationship between saccade task and emotional facial expressions (happy, angry, fearful, sad, neutral). The participants performed either pro- or antisaccades in response to peripherally presented facial expressions. Thus, these findings indicate impaired attentional control in social anxiety. This result may be due to a dysfunction in the prefrontal areas, which are involved in attentional control.

In contrast, Ansari and colleagues ${ }^{58}$ observed that individuals in the high anxiety group did not exhibit the commonly reported paradoxical improvement in saccade latency, whereas individuals in the low anxiety group did. In a more recent study, Derakshan et al ${ }^{59}$ identified that participants in the high anxiety group had longer correct antisaccade latencies than participants in the low anxiety group, and this effect 
was greater with threatening cues than positive or neutral ones. They also found that the two groups did not differ in terms of error rate in the antisaccade task.

Therefore, it can be concluded that OCD patients have a change in the latency of eye movement tasks in both saccadic and smooth pursuit, though no study found difference in the error rate when these patients were compared with healthy individuals. No studies were found that addressed change in eye movements in adults diagnosed with other subtypes of anxiety. One study involving social anxiety and two that divided the subjects into low and high anxiety groups demonstrated a change in eye movement in anxious individuals. Thus, more studies are required in this area to establish whether there is in fact a change in the eye movement pattern of anxious patients and whether this can be considered a biological marker.

\section{Conclusion}

SEM changes appear to be heavily involved in, and a possible marker for, the psychiatric disorders covered in this review. The changes occurring in the execution of eye movement tasks in patients with psychopathologies suggest that this movement is associated with the cognitive and motor systems. Specifically, bipolar patients presented different responses in relation to saccadic movement modifications. These responses appear to depend on the patient's disease phase. As such, there is a need for new experimental research looking at patients in various stages of mood swing to clarify these uncertainties, thus providing a greater understanding of the pathophysiology which will allow for the development of new treatment approaches for these patients.

Schizophrenic patients have difficulty inhibiting stimuli from the environment and directing attention to the target stimulus. Thus, we conclude that disorders of sensorimotor integration and of ocular tracking seem to be involved with one of the pathophysiological characteristics of schizophrenia.

With regards to the depressive patients, they presented slow responses to the stimulus and had varied in their response according to the type of depression. The studies with depression patients related to SEM demonstrated various results, mainly in terms of latency response; however, few studies address the issue considering other measures, for example, electrophysiological trials. Subjects with ADHD demonstrated difficulty executing planned movements and had impulsive responses, while, in anxiety patients, changes in latency were noted. The findings of the analyzed studies may result from impairment of the neural substrate in individuals with mental disorders. Although these changes have been observed, the data are still contradictory, thus cannot define that there are changes specific to each disorder. Future research is necessary to attempt to set a standard. Nevertheless, when patients are taking medications, it is important to keep in mind that these may be responsible for the changes observed and that different assessment methods may have different outcomes.

Even though such results are interesting for understanding the attention process associated with psychiatric patients, this study has certain limitations. The few existing studies about behavioral and electrophysiological pattern in psychiatric disorders, during the execution of the saccadic movements, demonstrate the need to improve the experimental paradigm, as well as the analysis methods used, since the results seem to be inconclusive due to methodological variability. Moreover, these few studies indicate conflicting results, which need to be investigated in future research.

\section{Disclosure}

The authors declare no conflicts of interest in this work.

\section{References}

1. Bremmer F, Kubischick M, Hoffman K, Krekelberg B. Neural dynamics of saccadic suppression. J Neurosci. 2009;29(40):12374-12383.

2. Jagla F, Jergelová M, Riecanský I. Saccadic eye movement related potentials. Physiol Res. 2007;56(6):707-713.

3. Findlay JM, Blythe HI. Saccade target selection: Do distractors affect saccade accuracy? Vision Res. 2009;49(10):1267-1274.

4. Thurtell MJ, Tomsak RL, Leigh RJ. Disorders of Saccades. Curr Neurol Neurosci Rep. 2007;7(5):407-416.

5. Fukushima J, Fukushima K, Chiba T, Tanaka S, Yamashita I, Kato M. Disturbances of voluntary control of saccadic eye movements in schizophrenic patients. Biol Psychiatry. 1988;23(7):670-677.

6. Luna B, Velanova K, Geier CF. Development of eye-movement control. Brain Cogn. 2008;68(3):293-308.

7. Everling S, Fischer, B. The antisaccade: a review of basic research and clinical studies. Neuropsychologia. 1998;36(9):885-899.

8. Hoffman JE, Subramaniam B. The role of visual attention in saccadic eye movements. Percept Psychophys. 1995;57(6):787-795.

9. Corbetta M, Akbudak E, Conturo TE, et al. A common network of functional areas for attention and eye movements. Neuron. 1998;21(4): 761-773.

10. McDowell JE, Clementz BA. The effect of fixation condition manipulations on antisaccade performance in schizophrenia: studies of diagnostic specificity. Exp Brain Res. 1997;115(2):333-344.

11. Sereno AB, Holzman PS. Antisaccades and smooth pursuit eye movements in schizophrenia. Biol Psychiatry. 1995;37(6):394-401.

12. Mueller SC, Ng P, Temple V, et al. Perturbed reward processing in pediatric bipolar disorder: an antisaccade study. J Psychopharmacol. 2010;24(12):1779-1784.

13. Jazbec S, McClure E, Hardin M, Pine DS, Ernst M. Cognitive control under contingencies in anxious and depressed adolescents: an antisaccade task. Biol Psychiatry. 2005;58(8):632-639.

14. Harris MS, Reilly JL, Thase ME, Keshavan MS, Sweeney JA. Response suppression deficits in treatment-naïve first-episode patients with schizophrenia, psychotic bipolar disorder and psychotic major depression. Psychiatry Res. 2009;170(2-3):150-156. 
15. Overton PG. Collicular dysfunction in attention deficit hyperactivity disorder. Med Hypotheses. 2008;70(6):1121-1127.

16. Pietrzak RH, Mollica CM, Maruff P, Snyder PJ. Cognitive effects of immediate-release methylphenidate in children with attentiondeficit/hyperactivity disorder. Neurosci Biobehav Rev. 2006;30(8): 1225-1245.

17. Gould TD, Bastain TM, Israel ME, Hommer DW, Castellanos FX. Altered performance on an ocular fixation task in attention-deficit/ hyperactivity disorder. Biol Psychiatry. 2001;50(8):633-635.

18. Munoz DP, Armstrong IT, Hampton KA, Moore KD. Altered control of visual fixation and saccadic eye movements in attention-deficit hyperactivity disorder. J Neurophysiol. 2003;90(1):503-514.

19. McDowell JE, Dyckman KA, Austin BP, Clementz BA. Neurophysiology and neuroanatomy of reflexive and volitional saccades: evidence from studies of humans. Brain Cogn. 2008;68(3):255-270.

20. Johnston K, Everling S. Neurophysiology and neuroanatomy of reflexive and voluntary saccades in non-human primates. Brain Cogn. 2008;68(3):271-283

21. McKeep RM, Keller EL. Deficits in saccade target selection after inactivation of superior colliculus. Nat Neurosci. 2004;7(7):757-763.

22. O'Driscoll GA, Alpert NM, Matthysse SW, Levy DL, Rauch SL, Holzman PS. Functional neuroanatomy of antisaccade eye movements investigated with positron emission tomography. Proc Natl Acad Sci U SA. 1995;92(3):925-929.

23. Carr LA, Nigg JT, Henderson JM. Attentional versus motor inhibition in adults with attention-deficit/hyperactivity disorder. Neuropsychology. 2006;20(4):430-441

24. Ilg UJ, Hoffmann KP. Motion perception during saccades. Vision Res. 1993;33(2):211-220.

25. Rommelse NN, Van der Stigchel S, Sergeant JA. A review on eye movement studies in childhood and adolescent psychiatry. Brain Cogn. 2008;68(3):391-414.

26. Hutton SB, Ettinger U. The antisaccade task as a research tool in psychopathology: a critical review. Psychophysiology. 2006;43(3): 302-313.

27. Munoz DP, Everling S. Look away: the anti-saccade task and the voluntary control of eye movement. Nat Rev Neurosci. 2004;5(3):218-228.

28. Burke MR, Barnes GR. Brain and behavior: a task-dependent eye movement study. Cereb Cortex. 2008;18(1):126-135.

29. Simó LS, Krisky CM, Sweeney JA. Functional neuroanatomy of anticipatory behavior: dissociation between sensory-driven and memorydriven systems. Cereb Cortex. 2005;15(12):1982-1991.

30. Picard HJ, Amado I, Bourdel MC, Landgraf S, Olié JP, Krebs MO Correlates between neurological soft signs and saccadic parameters in schizophrenia. Prog Neuropsychopharmacol Biol Psychiatry. 2009;33(4):676-681.

31. Holzman PS, Proctor LR, Hughes DW. Eye-tracking patterns in schizophrenia. Science. 1973;181(4095):179-181.

32. Holzman PS, Levy DL, Proctor LR. Smooth pursuit eye movements, attention, and schizophrenia. Arch Gen Psychiatry. 1976;33(12) $1415-1420$.

33. Landgraf S, Amado I, Bourdel MC, Leonardi S, Krebs MO. Memory-guided saccade abnormalities in schizophrenic patients and their healthy, full biological siblings. Psychol Med. 2008;38(6): 861-870.

34. American Psychiatric Association. Diagnostic and Statistical Manual of Mental Disorders. 4th edition (DSM-IV). Washington, DC, USA: APA; 1994.

35. Martin LF, Hall M, Ross RG, Zerbe G, Freedman R, Olincy A. Physiology of schizophrenia, bipolar disorder, and schizoaffective disorder. Am J Psychiatry. 2007;164(12):1900-1906.

36. Gooding DC, Mohapatra L, Shea HB. Temporal stability of saccadic task performance in schizophrenia and bipolar patients. Psychol Med. 2004;34(5):921-932.

37. Gooding DC, Grabowski JA, Hendershot CS. Fixation stability in schizophrenia, bipolar, and control subjects. Psychiatry Res. 2000;97(2-3):119-128.
38. Kathmann N, Hochrein A, Uwer R, Bondy B. Deficits in gain of smooth pursuit eye movements in schizophrenia and affective disorder patients and their unaffected relatives. Am J Psychiatry. 2003;160(4): 696-702.

39. Sweeney JA, Strojwas MH, Mann JJ, Thase ME. Prefrontal and cerebellar abnormalities in major depression: evidence from oculomotor studies. Biol Psychiatry. 1998;43(8):584-594.

40. Winograd-Gurvich C, Georgiou-Karistianis N, Fitzgerald PB, Millist L, White OB. Ocular motor differences between melancholic and non-melancholic depression. $J$ Affect Disord. 2006;93(1-3): 193-203.

41. Winograd-Gurvich C, Georgiou-Karistianis N, Fitzgerald PB, Millist L, White OB. Self-paced and reprogrammed saccades: differences between melancholic and non-melancholic depression. Neurosci Res. 2006;56(3):253-260.

42. Crevits L, Van den Abbeele D, Audenaert K, Goethals M, Dierick M. Effect of repetitive transcranial magnetic stimulation on saccades in depression: a pilot study. Psychiatric Res. 2005;135(2):113-119.

43. Mahlberg R, Steinacher B, Mackert A, Flechtner KM. Basic parameters of saccadic eye movements - differences between unmedicated schizophrenia and affective disorder patients. Eur Arch Psychiatry Clin Neurosci. 2001;251:205-210

44. Flechtner KM, Steinacher B, Sauer R, et al. Smooth pursuit eye movements of patients with schizophrenia and affective disorder during clinical treatment. Eur Arch Psychiatry Clin Neurosci. 2002;252(2):49-53.

45. Feifel D, Farber RH, Clementz BA, Perry W, Anllo-Vento L. Inhibitory deficits in ocular motor behavior in adults with attention-deficit/ hyperactivity disorder. Biol Psychiatry. 2004;56:333-339.

46. Goto Y, Hatakeyama K, Kitama T, et al. Saccade eye movements as a quantitative measure of frontostriatal network in children with ADHD. Brain Dev. 2010;32(5):347-355.

47. Siever LJ, Insel TR, Hamilton J, Nurnberger J, Alterman I, Murphy DL. Eye-tracking, attention and amphetamine challenge. J Psychiatr Res. 1987;21(2):129-135.

48. Clementz BA, Farber RH, Lam MN, Swerdlow NR. Ocular motor responses to unpredictable and predictable smooth pursuit stimuli among patients with obsessive-compulsive disorder. $J$ Psychiatry Neurosci. 1996;21(1):21-28.

49. Pallanti S, Grecu LM, Gangemi PF, et al. Smooth-pursuit eye movement and saccadic intrusions in obsessive-compulsive disorder. Biol Psychiatry. 1996;40(11):1164-1172.

50. Rosenberg DR, Dick EL, O'Hearn KM, Sweeney JA. Responseinhibition deficits in obsessive-compulsive disorder: an indicator of dysfunction in frontostriatal circuits. $J$ Psychiatry Neurosci. 1997;22(1):29-38.

51. Farber RH, Clementz BA, Swerdlow NR. Characteristics of open- and closed-loop smooth pursuit responses among obsessivecompulsive disorder, schizophrenia, and nonpsychiatric individuals. Psychophysiology. 1997;34(2):157-162.

52. Maruff P, Purcell R, Tyler P, Pantelis C, Currie J. Abnormalities of internally generated saccades in obsessive-compulsive disorder. Psychol Med. 1999;29(6):1377-1385.

53. Lencer R, Trillenberg P, Trillenberg-Krecker K, et al. Smooth pursuit deficits in schizophrenia, affective disorder and obsessive-compulsive disorder. Psychol Med. 2004;34:451-460.

54. van der Wee NJ, Hardeman HH, Ramsey NF, et al. Saccadic abnormalities in psychotropic-naive obsessive-compulsive disorder without co-morbidity. Psychol Med. 2006;36:1321-1326.

55. Spengler D, Trillenberg P, Sprenger A, et al. Evidence from increased anticipation of predictive saccades for a dysfunction of fronto-striatal circuits in obsessive-compulsive disorder. Psychiatry Res. 2006;143(1): 77-88.

56. Kloft L, Reuter B, Riesel A, Kathmann N. Impaired volitional saccade control: first evidence for a new candidate endophenotype in obsessivecompulsive disorder. Eur Arch Psychiatry Clin Neurosci. 2013;263(3): $215-222$. 
57. Wieser MJ, Pauli P, Mühlberger A. Probing the attentional control theory in social anxiety: an emotional saccade task. Cogn Affect Behav Neurosci. 2009;9(3):314-322.

58. Ansari TL, Derakshan N, Richards A. Effects of anxiety on task switching: evidence from the mixed antisaccade task. Cogn Affect Behav Neurosci. 2008;8(3):229-238.

59. Derakshan N, Ansari TL, Hansard M, Shoker L, Eysenck MW. Anxiety, inhibition, efficiency, and effectiveness. An investigation using antisaccade task. Exp Psychol. 2009;56(1):48-55.

60. Reilly JL, Lencer R, Bishop JR, Keedy S, Sweeney JA. Pharmacological treatment effects on eye movement control. Brain Cogn. 2008;68(3): 415-435.

61. Van Nechel C. Oculomotor anomalies from medications. Bull Soc Belge Ophtalmol. 2007;(304):179-184. French.

62. Larrison AL, Babin SL, Xing Y, et al. Effects of adjunct valproic acid on clinical symptoms and saccadic eye movements in schizophrenia. Hum Psychopharmacol. 2011;26(7):517-525.

63. Ibrahim HM, Tamminga CA. Schizophrenia: treatment targets beyond monoamine systems. Annu Rev Pharmacol Toxicol. 2011;51: 189-209.

64. Smyrnis N, Karantinos T, Malogiannis I, et al. Larger variability of saccadic reaction times in schizophrenia patients. Psychiatry Res. 2009;168(2):129-136.

65. Qiu L, Tian L, Pan C, et al. Neuroanatomical circuitry associated with exploratory eye movement in schizophrenia: a voxel-based morphometric study. PloS One. 2011;6(10):e25805.

66. van Tricht MJ, Nieman DH, Bour LJ, et al. Increased saccadic rate during smooth pursuit eye movements in patients at Ultra High Risk for developing a psychosis. Brain Cogn. 2010;73(3):215-221.

67. Burke MR, Barnes GR. Quantitative differences in smooth pursuit and saccadic eye movements. Exp Brain Res. 2006;175(4):596-608.

68. Fuchs AF. Saccadic and smooth pursuit eye movements in the monkey. J Physiol. 1967;191(3):609-631.

69. O'Driscoll GA, Strakowski SM, Alpert NM, et al. Differences in cerebral activation during smooth pursuit and saccadic eye movements using positron-emission tomography. Biol Psychiatry. 1998;44(8):685-689.

70. Holzman PS. Recent studies of psychophysiology in schizophrenia. Schizophr Bull. 1987;13(1):49-75.

71. Mazhari S, Price G, Dragović M, Waters FA, Clissa P, Jablensky A. Revisiting the suitability of antisaccade performance as an endophenotype in schizophrenia. Brain Cogn. 2011;77(2):223-230.

72. Thaker GK. Neurophysiological endophenotypes across bipolar and schizophrenia psychosis. Schizophr Bull. 2008;34(4):760-773.

73. Kim JS, Baek JH, Choi JS, Lee D, Kwon JS, Hong KS. Diagnostic stability of first-episode psychosis and predictors of diagnostic shift from non-affective psychosis to bipolar disorder: a retrospective evaluation after recurrence. Psychiatry Res. 2011;188(1):29-33.

74. El-Hage W, Surguladze SA. Emerging treatments in the management of bipolar disorder - focus on risperidone long acting injection. Neuropsychiatr Dis Treat. 2010;6:455-464.

75. Baumann O, Ziemus B, Luerding R, Schuierer G, Bogdahn U, Greenlee MW. Differences in cortical activation during smooth pursuit and saccadic eye movements following cerebellar lesions. Exp Brain Res. 2007;181(2):237-247.

76. Baier B, Stoeter P, Dieterich M. Anatomical correlates of ocular motor deficits in cerebellar lesions. Brain. 2009;132(Pt 8):2114-2124.

77. Martin LF, Olincy A, Ross RG, et al. Cerebellar hyperactivity during smooth pursuit eye movements in bipolar disorder. $J$ Psychiatr Res. 2011;45(5):670-677.

78. Gooding DC, Tallent KA. The association between antisaccade task and working memory task performance in schizophrenia and bipolar disorder. J Nerv Ment Dis. 2001;189(1):8-16.

79. Garro IM, Camillo SO, Nóbrega MP. Depressão em graduandos de Enfermagem [Depression among nursing undergraduate students]. Acta Paulista de Enfermagem. 2006;19(2):162-167. Portuguese.
80. Lee S, Jeong J, Kwak Y, Park SK. Depression research: where are we now? Mol Brain. 2010;3:8.

81. Muñoz RF, Cuijpers P, Smit F, Barrera AZ, Leykin Y. Prevention of major depression. Annu Rev Clin Psychol. 2010;6:181-212.

82. Ridderinkhof KR, van den Wildenberg WP, Segalowitz SJ, Carter CS. Neurocognitive mechanisms of cognitive control: the role of prefrontal cortex in action selection, response inhibition, performance monitoring, and reward-based learning. Brain Cogn. 2004;56(2):129-140.

83. Levy DL, Yasillo NJ, Dorus E, et al. Relatives of unipolar and bipolar patients have normal pursuit. Psychiatric Res. 1983;10(4):285-293.

84. Carr L, Henderson J, Nigg JT. Cognitive control and attentional selection in adolescents with ADHD versus ADD. J Clin Child Adolesc Psychol. 2010;36(6):726-740.

85. Smyrnis N, Evdokimidis I, Stefanis NC, et al. Antisaccade performance of 1,273 men: effects of schizotypy, anxiety, and depression. J Abnormal Psychol. 2003;112(3):403-414.

86. Klein CH, Raschke A, Brandenbusch A. Development of pro- and antisaccades in children with attention-deficit hyperactivity disorder (ADHD) and healthy controls. Psycophisiology. 2003;40(1):17-28.

87. Karatekin C. Improving antisaccade performance in adolescents with attention-deficit/hyperactivity disorder (ADHD). Exp Brain Res. 2006;174(2):324-334

88. Adams ZW, Roberts WM, Milich R, et al. Does response variability predict distractibility among adults with attention-deficit/hyperactivity disorder? Psychol Assess. 2011;23(2):427-436.

89. Mazer J. Spatial attention, feature-based attention, and saccades: three sides of one coin? Biol Psychiatry. 2011;69(12):1147-1152.

90. Hanisch C, Radach R, Holtkamp K, Herpertz-Dahlmann B, Konrad K. Oculomotor inhibition in children with and without attention-deficit hyperactivity disorder (ADHD). J Neural Transm. 2006;113(5):671-684.

91. Rommelse NN, Van der Stigchel S, Witlox J, et al. Deficits in visuo-spatial working memory, inhibition and oculomotor control in boys with ADHD and their non-affected brothers. J Neural Transm. 2008;115(2):249-260.

92. Castillo AR, Recondo R, Asbahr FR, Manfro GG. Trasntorno de ansiedade [Anxiety disorders]. Rev Bras Psiquiatr. 2000;22(2):20-23. Portuguese.

93. Kinrys G, Wigant LE. Anxiety disorders in women: does gender matter to treatment? Rev Bras Psiquiatr. 2005;27 Suppl 2:S43-S50. Portuguese.

94. Berggren N, Richards A, Taylor J, Derakshan N. Affective attention under cognitive load: reduced emotional biases but emergent anxiety-related costs to inhibitory control. Front Hum Neurosci. 2013;7:188.

95. Robinson OJ, Krimsky M, Grillon C. The impact of induced anxiety on response inhibition. Front Hum Neurosci. 2013;7:69.

96. Chen J, Wang Z, Wu Y, et al. Differential attentional bias in generalized anxiety disorder and panic disorder. Neuropsychiatr Dis Treat. 2013;9:73-80.

97. Gooding DC, Basso MA. The tell-tale tasks: a review of saccadic research in psychiatric patient populations. Brain Cogn. 2008;68(3):371-390.

98. Kennard C. Disorders of higher gaze control. Handb Clin Neurol. 2011;102:379-402.

99. Jaafari N, Rigalleau F, Rachid F, et al. A critical review of the contribution of eye movement recordings to the neuropsychology of obsessive compulsive disorder. Acta Psychiatr Scand. 2011;124(2):87-101.

100. Tien AY, Ross DE, Pearlson G, Strauss ME. Eye movements and psychopathology in schizophrenia and bipolar disorder. J Nerv Ment Dis. 1996;184(6):331-338. 
Neuropsychiatric Disease and Treatment

Dovepress

\section{Publish your work in this journal}

Neuropsychiatric Disease and Treatment is an international, peerreviewed journal of clinical therapeutics and pharmacology focusing on concise rapid reporting of clinical or pre-clinical studies on a range of neuropsychiatric and neurological disorders. This journa is indexed on PubMed Central, the 'PsycINFO' database and CAS.

The manuscript management system is completely online and includes a very quick and fair peer-review system, which is all easy to use. Visit http://www.dovepress.com/testimonials.php to read real quotes from published authors.

Submit your manuscript here: http://www.dovepress.com/neuropsychiatric-disease-and-treatment-journal 